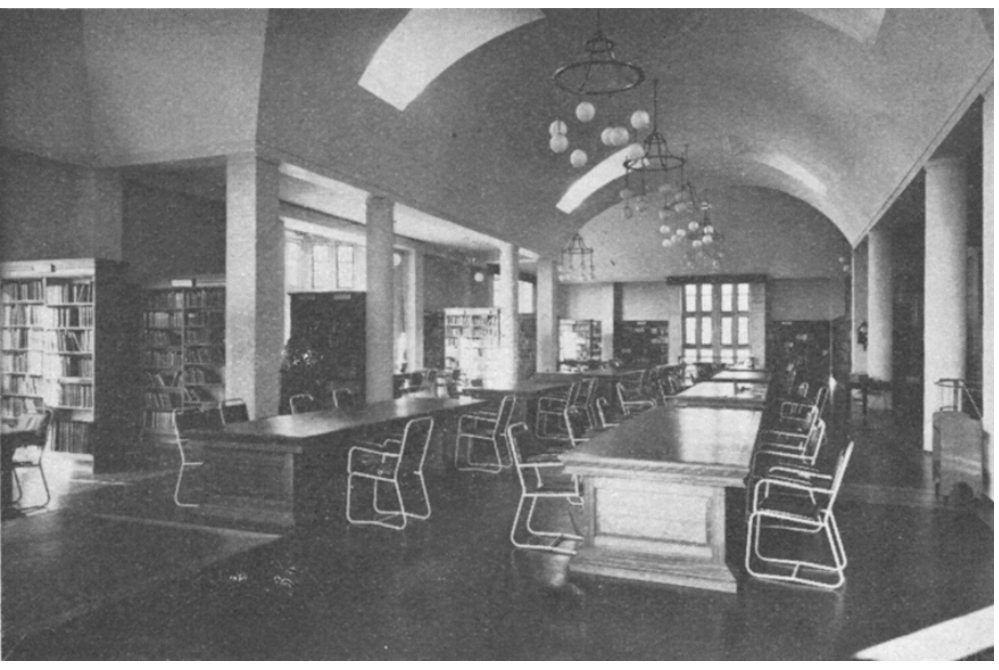

Fig. 4. University of Exeter: Reading Room, Roborough Library

realized; but since then, despite substantial efforts made by the College to acquire suitable premises, the influx of students has made it necessary for some to live in private lodgings for a part of their stay in Exeter. Of the 1,029 full-time students, who come not only from the south-west of England but also from London and elsewhere in Eng. land and Wales and from many overseas countries, $\mathbf{5 5 8}$ live in College halls and the remainder live either at home or in lodgings.

Since its incorporation as a University College, remarkable strides have been made in the training provided for the London external degrees in arts, science, economics and law. The number and quality of the degrees obtained serve as an indication of the high academic status which has been attained. Nor has this progress been confined to

to. capacity with nearly 100,000 volumes. The erection on a rather elevated site of a new block for the Faculty of Arts is imminent. The architect of the Singer and Hatherly Laboratories and the Roborough Library and two Halls of Residence, Mr. E. Vincent Harris, is giving the University a chapel, to be known as the Mary Harris Memorial Chapel. Building will shortly begin.

Situated still higher on the southern slope of University campus are the Mardon and Reed Halls of residence for men, while on the top of the hill, which since the War has been levelled, is located a large playing field. By its side is the Taylor Pavilion - a memorial to the late principal, Sir Thomas Taylor. The facilities for sport have just been extended by the erection of a boat-house at Countess Weir on the bank of the Exe canal.

Contiguous with the campus is Knightley, in which the Faculty of Law and the Overseas Students' and Extra-mural Departments are housed, and Thornlea, which, together with a new building close by, accommodates the Department of Education and Psychology and the Institute of Education.

An important policy of the College was to make it residential so far as possible, and in the years immediately prior to 1946 this aim was almost undergraduate training, for considerable attention has been given to postgraduate training and research. In the sciences, research has been a strong feature, as may be seen from the number of original papers published in the scientific journals and the number of Ph.D.'s which have been gained by Exeter students. Facilities for research in astronomy are also available in the Norman Lockyer Observatory at Sidmouth, which for many years past has been closely associated with the University College. On the arts side, abundant material for investigation has been rendered available to the students by the recent agreement of the Dean and Chapter of the Cathedral to entrust the College Librarian with the care of the unique library of the Cathedral.

For the time being, the University of Exeter will develop and consolidate its existing Faculties of Arts (including Education), Science, Social Studies (including Economics, Social and Public Administration) and Law. Nevertheless, it is safe to say that the possibility of extending its usefulness in other fields of learning and research will always receive the constant vigilance and attention of the new University. Its aspirations and aims will always be to serve mankind, the United Kingdom and especially the inhabitants of the south-west of England.

\title{
INTERACTION OF SPRAY PROGRAMMES AND INSECT POPULATIONS
}

\begin{abstract}
$\mathrm{A}^{\mathrm{N}}$ $\mathbf{N}$ open day at East Malling Research Station on September 21 provided an opportunity for some two hundred members to hear and discuss contributions by staff of the Entomology and Plant Protective Chemistry Sections on the interaction of spray programmes and insect populations. Following the usual custom, members of the official advisory services attended a similar programme on the previous day.

It was pointed out that the present investigations, which are devoted to a study of the fruit-tree red spider mite, Metatetranychus ulmi (Koch), its natural enemies, and the effect of spray chemicals on
\end{abstract}

populations of both, are a collaborative project shared by entomologists, plant-protective chemists and plant pathologists. The entomologists are primarily concerned with the biological and ecological problems involved, the chemists with the mechanism of action by which the spray materials in common use affect the insects and mites and, since there is ample evidence to show that fungicides as well as insecticides sometimes prove harmful to the beneficial fauna, the plant pathologists also become intimately involved in such a project. At the present time only a progress report is possible; the causes leading to the appearance of $M$. ulmi as a pest are fairly clear, 
but much detailed work lies ahead before a spray programme can be devised by which beneficial insects are retained in the fruit plantation while pests and diseases not amenable to control by natural agencies are kept in check by the application of chemicals.

Historically, $M . u l m i$ has been noticed as a pest in English orchards only during the past thirty years, its appearance coinciding with the use of tar distillate washes which became general from 1925 onwards. More recently, infestations have been accentuated following the use of DDT and parathion as post-blossom sprays and, in some Kent and Essex apple orchards, the red spider mite, Tetranychus telarius L., has appeared as a pest for the first time following frequent applications of parathion during the summer months. Examples such as these clearly indicate that harmful side-effects may arise from the use of new spray chemicals ; and since such materials are often in the hands of growers before members of research institutions have time to evaluate their full effects on the orchard fauna, it is only prudent for them to be used on a small scale at first, followed by close and frequent observation, so that remedial measures can be taken at the earliest moment should the need arise.

As a result of intensive surveys in both sprayed and derelict orchards, about a hundred species, comprising approximately equal numbers of insects, and spiders and mites, have been found that utilize in varying degrees $M . u l m i$ as a source of food. Striking differences occur between the fauna of these two orchard types. In derelict orchards a large number of species occur, forming a continuous succession, so that predators are represented in strength throughout the year, attacking the mite during the whole of its active period and also feeding on the winter eggs. In sprayed orchards there is usually a total absence, or at least a very marked reduction, of predators until June; for the remainder of the summer the species are much fewer, although individual insects such as the black-kneed capsid, Blepharidopterus angulatus (Fall.), are often present in considerably greater numbers than in unsprayed orchards. Only minor annual fluctuations of both species and total populations occur in the derelict orchard, whereas both show violent variations in the sprayed orchard. In part this can be accounted for by the direct effect of sprays, but alternative sources of food, other than phytophagous mites, readily available only in derelict orchards, must also be an important contributory factor.

Among the insect predators, those occurring most commonly include species of Miridae (Psallus ambiguus (Fall.)), Campylomma verbasci (M.-D.), Atractotomus mali (M.-D.), Orthotylus marginalis Reut., Phytocoris spp., Malacocoris chlorizans (Panz.), Blepharidopterus angulatus (Fall.)), Anthocoridae (Anthocoris nemorum (L.), Orius majusculus (Reut.)), Coccinellidae (Stethorus punctillum (Wei.)) and Coniopterygidae (Conwentzia spp.). Of the spiders, only members of the families Theridiidae and Linyphiidae readily feed on $M$. ulmi; and the predacious mites are predominantly species of the genus Typhlodromus, of which only $T$. tiliae Oudms. becomes abundant in sprayed orchards.

The relative importance of each predator has not yet been fully assessed; but field observations indicate that all the insects named possess the desirable character of being 'density dependent' in the sense that numbers increase in the presence of ample food, whereas the spiders, with at most one generation a year, increase their rate of feeding when food is plentiful. The latter group attack both beneficial and pest species indiscriminately, and are therefore of doubtful value except under conditions where the pest predominates. Judged by the usual standards, Typhlodromus tiliae is an inefficient predator, as its behaviour pattern both in respect to leaf preference and position on the leaf is not well integrated with that of $M$. ulmi; furthermore, it has a low feeding capacity and can develop and reproduce on plant protein or other species of mites.

As an introduction to the orchard trials in progress at East Malling, the effects arising from two extreme ecological situations were described in very simplified form. In one example, a succession of natural enemies present in the same environment as the prey and attacking it throughout its life-cycle resulted in a continuous depression of prey population similar to that already observed in connexion with $M$. ulmi in derelict orchards. But under such conditions alternative sources of food are necessary if predator populations are to be maintained. As yet, relatively little is known about this aspect; but experiments have demonstrated that the Mirids and Typhlodromid mites are partly phytophagous, and it is also clear that the much richer fauna, including pest species such as aphids and Psylla mali Schmid., occurring in the unsprayed orchard, can provide adequate food for the predators. In contrast to the above, the violent oscillations associated with the presence of only a single species of predator and prey were outlined. Examples of this type are rarely documented in Nature except in specialized ecological niches, but it appears that man may have created such a situation in sprayed orchards between $M$. $u m i$ as prey and $B$. angulatus as predator. A composite picture from the records of two experimental orchards over the past three years has shown one complete oscillation, two stages of which were available as a visual demonstration. In one orchard, where the population of $M$. ulmi was approaching its peak and predator populations were increasing annually but not yet large enough to cause suppression, the foliage was markedly bronzed, whereas in another orchard, where mite populations suffered a severe reversal in 1954, the fresh green foliage bore no evidence of injury, even in the absence of any acaricidal sprays.

Investigations concerning the effect of spray chemicals on populations of $M$. ulmi and its predators are still in the analytical phase, being concentrated on elucidating the harmful effects of insecticides in general use during the pre-blossom period, together with a similar study of fungicides when applied throughout the spraying season. Sufficient data have been obtained to demonstrate that, by ovicidal or contact action, DNC(dinitrocresol)-petroleum applied at the delayed dormant stage destroys practically all the predators which would normally be present before June; DDT, by contact or residual action, has a similar effect when applied at the mouse-ear stage ; lime-sulphur drastically reduces Typhlodromid mites and causes a slight reduction of Mirids. Studies of the age structure of certain Mirid species following the use of captan ( $N$-trichloromethylthio-cyclohex4-ene-1 : 2-dicarboxyimide), a fungicide considered non-toxic to these insects, have indicated that even the physical effect of sprays applied at high pressure by the conventional hydraulic equipment may seriously affect predator populations. 
The very harmful effect on beneficial species of certain insecticides used for controlling pests during the pre-blossom period has therefore been clearly demonstrated ; it can also be deduced from indirect evidence that chemicals in current use against the apple sawfly, Hoplocampa testudinea Klug, will produce similar results. In addition, it has been shown that the range of predators occurring from June onwards is unable to prevent large oscillations in the population of $M$. ulmi. The aim, therefore, is to modify the spray programme in order to allow the establishment of one or more efficient predators early in the season. Further advances along these lines will be largely dependent on the chemical studies now in progress concerning the fate of materials after deposition on the tree. By increasing knowledge in this sphere, it may be possible to achieve rather more selective action by choice of chemical and variations in its time of application, concentration or formulation.

\section{METABOLISM OF NITROGEN IN PLANTS}

A SESSION on the nitrogen metabolism of plants, under the chairmanship of Prof. M. Skene, was held at Bristol on September 2 by Section K (Botany) of the British Association. Problems of the assimila. tion of nitrogen and the synthesis of amino-acids and proteins in plant tissues formed one of the central themes of the discussion. Three speakers gave accounts of some of the work in progress in the Department of Botany of the University of Bristol, and Prof. H. E. Street (University College of Swansea) discussed the potentialities of the aseptic culture of excised roots as a means of studying the assimilation and metabolism of nitrogen.

The part played by different cellular structures in the synthesis of proteins was dealt with by Prof. E. W. Yemm (Bristol). Earlier views, derived chiefly from genetical considerations, have suggested that the nucleus is the most important centre of protein synthesis in the cell, and this hypothesis has been developed particularly by Caspersson. The conspicuous changes of nucleic acids associated with protein synthesis in some animal cells and in microorganisms provide the chief support for the hypothesis. During recent years several lines of evidence have been advanced which are difficult to reconcile with the view that protein synthesis is entirely localized in or on the surface of the nucleus. For example, Brachet and his collaborators have shown that non-nucleated fragments of some plant and animal cells continue to synthesize proteins actively. In addition, experiments with isotopically labelled amino-acids indicate that they are rapidly incorporated into particulate structures of the cytoplasm. Ultramicroscopic particles, which may be separated by differential centrifugation and which contain most of the ribonucleic acid of the cytoplasm, are especially active in the incorporation of radiocarbon-labelled amino-acids. It has therefore been suggested that these cytoplasmic microsomes are the chief centres of protein synthesis in cellular metabolism.

There are, however, several difficulties in the interpretation of data based solely on the incorporation of labelled amino-acids into cell proteins. The study of proteinases and other plant enzymes has shown that they promote exchange reactions, such as transpeptidation and transamidation, so that replacement of amino-acids does not necessarily imply a new synthesis of protein. Experiments with detached leaves and roots of barley have shown that, even under conditions in which a net loss of proteins occurs in the tissues, there is nevertheless appreciable incorporation of the isotope nitrogen-15 into the cytoplasnic proteins. On the other hand, under conditions in which an active synthesis of new proteins occurs, such as in young seedlings, it is possible to detect the incorporation of nitrogen-15 into all the cell components separated by differential centrifugation within a few hours of supplying the isotope as an ammonium salt. The results so far obtained from a study of the assimilation of nitro. gen-15 by barley seedlings suggest that the primary synthesis of new protein is not confined to microsomes but may also take place in nuclei, plastids and mitochondria of the cells.

Dr. A. J. Willis (Bristol) discussed the assimilation by plants of simple inorganic forms of nitrogen, such as nitrates, nitrites and ammonium salts, and gave an account of experiments in which an attempt was made to trace the early stages of the assimilation process and to determine the nature of the primary products formed in young roots of barley. Under conditions favouring a rapid uptake of nitrates, nitrites or ammonia by excised roots, it was found that a marked increase of glutamine, accompanied by smaller quantities of asparagine, occurred in the tissues. During short periods of assimilation more than 90 per cent of the nitrogen metabolized could be recovered as amides, chiefly glutamine. By using nitrogen-15 as a tracer it was possible to obtain decisive evidence that the amides were primary products of assimilation. When the roots were supplied with an ammonium salt containing about 30 atom per cent excess of nitrogen-15, the isotopic abundance in the amino- and amide-groups of glutamine rapidly approached that of the ammonia supplied. Some differences were apparent in the amount of amides formed when different sources of nitrogen were provided : nitrite and ammonia were more rapidly metabolized in the young roots than nitrate, the step nitrate to nitrite being a slow one. All the data support the hypothesis that nitrite, hydroxylamine and ammonia are intermediates in the assimilation of nitrate and that glutamine is a primary product of synthesis.

Other metabolic activities of the roots are closely associated with the assimilation of nitrogen. The rate of respiration, measured by the uptake of oxygen and the production of carbon dioxide, is greatly increased when a suitable source of nitrogen is provided. The most rapid responses are obtained with ammonia and nitrites, and there are many indications that the rise in respiration is coupled with synthetic activities in the tissues rather than with salt uptake. An extensive breakdown of carbohydrate sustains the assimilation processes in excised roots for a limited period, and analytical data indicate that both the respiratory carbon dioxide and the carbon skeletons for the synthesis of amides are mainly 